\title{
Letter to the Editor: ESI-MS-MS library of 1,253 compounds for application in forensic and clinical toxicology
}

\author{
François-Ludovic Sauvage $•$ Pierre Marquet
}

Published online: 27 January 2010

(C) Springer-Verlag 2010

We read with great interest the article entitled "ESI-MS-MS library of 1,253 compounds for application in forensic and clinical toxicology" by Dresen et al. [1], presenting an electrospray ionization tandem mass spectrometry library for 1,253 compounds relevant in clinical and forensic toxicology, developed using a hybrid tandem mass spectrometer with a linear ion trap. Using information-dependent acquisition (IDA) algorithms, the authors previously developed a "multi-target screening" method with 301 drugs in which multiple reaction monitoring (MRM) was used for the survey scan and the enhanced product ion (EPI) scan as dependent scan mode [2]. A library was then generated with the EPI spectra obtained at collision energies of 20,35, and $50 \mathrm{eV}$ in the positive mode. The more recent paper presents a "new" library built using the automatic collision energy spread feature, which sums the three independent spectra generated [1].

As we mentioned three years ago, the enhanced mass scan mode can also be used for the survey scan [3]. In particular, a library of EPI spectra for more than 1,000 compounds, acquired at collision energies of 15,40 , and $65 \mathrm{eV}$ and summed using the collision energy spread

This letter to the editor is related to the "Technical Note" to be found at doi:10.1007/s00216-009-3084-2.

\author{
F.-L. Sauvage $(\bowtie) \cdot$ P. Marquet \\ INSERM UMR-S850, \\ Limoges, France \\ e-mail: fl.sauvage@unilim.fr \\ F.-L. Sauvage $\cdot$ P. Marquet \\ CHU Limoges, Department of Pharmacology-Toxicology, \\ Limoges, France
}

feature has already been built. Moreover, because of their specificity and reproducibility, these EPI spectra have also recently been proven to be helpful for elucidation of metabolites $[4,5]$ or for identification of peaks interfering with one (or more) MRM transitions [6]. Dresen and coworkers did not cite our first paper (published in Clinical Chemistry) in their work [3]. They — and, we are afraid, the reviewers of this paper-may not have identified this previous work as relevant to their study, despite the obvious similarities in the use of these composite EPI spectra [3]. However, we must admit that, owing to the use of the total scan mode as survey scan, our method is much less selective than the target screening method reported here by Dresen et al., i.e. much more suited to clinical or forensic toxicology - where the question asked by clinicians or the judiciary is whether an individual had been intoxicated at all, and not whether they had taken a molecule in a necessarily limited pre-defined list, particularly regarding metabolites.

\section{References}

1. Dresen S, Gergov M, Politi L, Halter C, Weinmann W (2009) Anal Bioanal Chem 395(8):2521-2526

2. Mueller CA, Weinmann W, Dresen S, Schreiber A, Gergov M (2005) Rapid Commun Mass Spectrom 19(10):1332-1338

3. Sauvage FL, Saint-Marcoux F, Duretz B, Deporte D, Lachâtre G, Marquet P (2006) Clin Chem 52(9):1735-1742

4. Picard N, Dridi D, Sauvage FL, Boughattas NA, Marquet P (2009) J Sep Sci 32(13):2209-2217

5. Sauvage FL, Picard N, Saint-Marcoux F, Gaulier JM, Lachâtre G, Marquet P (2009) J Sep Sci 32(18):3074-3083

6. Sauvage FL, Gaulier JM, Lachâtre G, Marquet P (2008) Clin Chem 54(9):1519-1527 